\title{
In-hospital prognostic value of on admission creatinine clearance in patients with acute coronary syndrome
}

Madhurima Saha', M M Zahurul Alam Khan², Md Zahid Alam³, Mohammad Omar Faruq ${ }^{4}$, A S M Areef Ahsan $^{5}$, Debasish Kumar Saha ${ }^{6}$

\begin{abstract}
Objective: To find out association between creatinine clearance rate (CCR) and in-hospital outcome of acute coronary syndrome (ACS).

Methodology: This prospective observational study was carried on 100 patients with acute coronary syndrome, in Coronary Care Unit (CCU) of BIRDEM General Hospital, Shahbag, Dhaka, over a period of six months from July 1, 2012 to December 31, 2012.

Results: Subjects were divided into three groups $(A: C C R>60, B: C C R-30-60$ and $C: C C R<30)$ depending on their $C C R(\mathrm{ml} / \mathrm{min})$. Mean creatinine clearance rate was 56.15 ( \pm 29.57$) \mathrm{ml} / \mathrm{min}$ and mean serum creatinine level was 3.68 ( \pm 2.59$) \mathrm{mg} / \mathrm{dl}$. Among 20 patients of Group A subjects $15(75 \%)$ were discharged in a stable condition. $2(10 \%)$ and $3(15 \%)$ patients developed isolated left ventricular failure (LVF) and isolated hypotension respectively. No patient died in this group and none of them developed any bleeding episode (epistaxis, melaena, haematemesis, haematochezia or per vaginal bleeding etc), sepsis or multi-organ dysfunction syndrome (MODS). Among 35 patients of Group B subjects 8(22.8\%) were discharged in a stable condition. $9(25.7 \%)$ and $6(17.1 \%)$ patients developed isolated LVF and isolated hypotension respectively. 2(5.7\%) patients died in this group and 7(20\%), 2(5.7\%),1(2.8\%) patients developed bleeding episode, sepsis and MODS respectively. Among 45 patients of Group C subjects 3(6.6\%) were discharged in a stable condition. 12(26.7\%) and $8(17.7 \%)$ patients developed only LVF and only hypotension respectively. 4(8.8\%) patients died in this group during their hospital stay and 11(24.4\%), 3(6.6\%) and 4(8.8\%) patients developed bleeding episode, sepsis and MODS respectively. ANOVA test suggested that decreased creatinine clearance rate was significantly related to poor clinical outcome $(P<0.05)$.

Conclusion: This study showed that decreased creatinine clearance is directly related to poor outcome of acute coronary syndrome. So subjects with ACS should be closely monitored for decreased creatinine clearance rate to avoid life threatening complications. And subjects with renal impairment suffering from ACS should be closely observed as patients with decreased CCR has poor clinical outcome.
\end{abstract}

\section{Introduction}

Acute coronary syndrome (ACS) refers to a constellation of

1. Dr. Madhurima Saha, FCPS (Medicine), Registrar, Dept of Critical Care Medicine, BIRDEM General Hospital, Shahbag, Dhaka-1000

2. Dr. MM Zahurul Alam Khan, FCPS (Medicine), MD (Cardiology), Professor, Dept of Cardiology, BIRDEM General Hospital, Shahbag, Dhaka-1000

3. Dr. Md Zahid Alam, FCPS (Medicine), Associate Professor, Dept of Cardiology, BIRDEM General Hospital, Shahbag, Dhaka-1000

4. Dr. Mohammad Omar Faruq, MD, FACP, FACEP, FCCM, FCPS, Professor, Dept of Critical Care Medicine, BIRDEM General Hospital, Shahbag, Dhaka-1000

5. Dr. A.S.M. Areef Ahsan, FCPS (Medicine), MD (Chest), MD (Critical Care Medicine), Associate Professor and Head, Dept of Critical Care Medicine, BIRDEM General Hospital, Shahbag, Dhaka-1000

6. Dr. Debasish Kumar Saha, FCPS (Medicine), Registrar, Dept of Critical Care Medicine, BIRDEM General Hospital, Shahbag, Dhaka-1000

\section{Corresponding Author:}

Dr. Madhurima Saha

Registrar, Department of Critical Care Medicine

BIRDEM General Hospital, Shahbag, Dhaka-1000

E-mail: madhurimasaha82@gmail.com clinical symptoms caused by acute myocardial ischemia. ${ }^{1,2}$ ACS encompasses acute myocardial infarction (MI) [both ST-elevation myocardial infarction (STEMI) and non-ST-elevation myocardial infarction (NSTEMI)] and unstable angina (UA). Acute MI is defined as rise of cardiac biomarkers with at least one of the following: ischemic cardiac pain, ECG changes indicative of new ischemia (ST-T change or appearance of new bundle branch block), development of pathological Q waves, imaging evidence of new loss of viable myocardium or new regional wall motion abnormality.UA is diagnosed on the basis of any one of the following criteria: rest angina, new-onset angina, and increasing angina (increasing in intensity, duration, and/or frequency). ${ }^{3}$

Many studies have demonstrated that renal insufficiency is an independent risk factor for cardiovascular morbidity and for all-cause as well as cardiovascular death in both the general population and patients with cardiovascular disease. ${ }^{4}$ In particular, recent studies have shown that any stage of renal dysfunction (mild to severe) is an independent risk factor for short- and long-term morbidity among patients with MI, even after administration of fibrinolytics. ${ }^{4-7}$ However, there are limited data about this relationship in patients presenting with non-ST-segment-elevation MI and unstable angina. ${ }^{8}$ 
Epidemiological studies and clinical trials shows that renal function can be measured by serum creatinine, blood urea nitrogen, and glomerular filtration rate (GFR) or estimated creatinine clearance (CCR). ${ }^{9-13}$ Renal damage is detectable in its early stages through the use of serum creatinine, but it has significant age \& sex variation. But CCR can usually detect the real scenario of renal status to some extent. ${ }^{14}$ Glomerular filtration rate (GFR) accurately expresses the renal function. Though GFR is considered the gold standard to detect the real scenario of renal status but CCR can reflect the renal function like GFR and it is easier to calculate in lab and can be calculated by different formula. ${ }^{16-18}$ The most commonly used one is: age and gender based algorithms, such as the Cockcroft-Gault formula, which has been applied to improve the accuracy of serum creatinine measures. The formula is as follows:

$\mathrm{CCR}(\mathrm{ml} / \mathrm{min})=[140$-age $($ years $) \mathrm{x}$ weight $(\mathrm{kg})] /$ serum creatinine $(\mathrm{mg} / \mathrm{dl}) \times \mathrm{72}]$. The result is multiplied by 0.85 for women.

The most common cause of death in patients with impaired renal function is ischemic heart disease (IHD).${ }^{15}$ Although it is not possible to asses clinically, the impact of impaired renal function on ACS, but studies have found significant association between impaired renal function and mortality and morbidly of ACS. Several reports suggested that severe renal disease is a significant independent predictor of cardiovascular event. ${ }^{16-21}$

Data regarding in-hospital morbidity and mortality of patients with ACS with decreased CCR are limited globally and very limited in our country. So, this study aims to determine the relationship between the CCR at the time of in-patient admission and the in-hospital outcome of patients with ACS.

\section{Materials and Methods}

This prospective observational study was carried out on 100 consecutive subjects aged 40-66 years suffering from ACS in CCU of BIRDEM General Hospital, irrespective of preadmission CCR and renal function status. The primary objective of this study was to find out association between CCR and in-hospital outcome of ACS and secondary objectives are to observe the level of creatinine clearance rate in study subjects, to observe the in-hospital outcome of the patients in different stages of CCR. We included all patients admitted into CCU with diagnoses of ACS. We excluded the subjects with old myocardial infarction, stable coronary artery disease, acquired valvular heart disease, congenital heart disease. Patient who had diagnostic dilemma about ACS, who refused to be included in the study, patients below 18 years and known psychiatric patients were also excluded from the study. The objective of the study was discussed in details with the patients or their attendants before their decision to willingly enroll into the study. Clinical examination, relevant laboratory tests, X-ray chest, electrocardiogram (ECG) and 2D-echocardiogram with color doppler were done. Demographic information like age and gender were prospectively recorded. Past medical and clinical history by prior medical records were obtained and were substantiated if available before conduction of the study.

All subject under the study $(n=100)$ were divided into three groups depending on their CCR $(\mathrm{ml} / \mathrm{min})$ : Group A( CCR $>60$ $\mathrm{ml} / \mathrm{min}$ ), group B (CCR 30-60 $\mathrm{ml} / \mathrm{min}$ ) and group C (CCR $<30 \mathrm{ml} / \mathrm{min}$ ). $20 \%$ belonged to group A, $35 \%$ belonged to group B and $45 \%$ belonged to group C. All the relevant collected data were compiled on a master data sheet. Proportion of the findings was expressed as percentage and analysis were done using SPSS for windows version 17.0. P value was calculated using ANOVA test and considered to be significant when it was $<0.05$. All patients were followed up until discharge home or transfer to in-patient unit. None of the study subjects stayed in CCU for more than 28 days.

Prior to the commencement of the study permission was obtained from Ethical Review Board of BIRDEM Academy. Informed consent was obtained from each patient or his/her legal guardian.

Results

Age of study subjects ranged from 47 to 64 years with mean age of 59.91 years with standard deviation of mean $(\mathrm{SD}) \pm 6.68$ years.

Table I : shows distribution of the study subjects of different CCR groups (A, B, C) according to age.

\begin{tabular}{|c|c|c|c|c|c|c|c|}
\hline \multirow{3}{*}{$\begin{array}{l}\text { Age groups of } \\
\text { the study subjects } \\
\text { in years }\end{array}$} & \multicolumn{2}{|c|}{ Group A } & \multicolumn{2}{|c|}{ Group B } & \multicolumn{2}{|l|}{ Group C } & \multirow[t]{3}{*}{ p- value } \\
\hline & \multicolumn{2}{|c|}{$\mathrm{CCR}>60 \mathrm{ml} / \mathrm{min}$} & \multicolumn{2}{|c|}{$\mathrm{CCR}=30-60 \mathrm{ml} / \mathrm{min}$} & \multicolumn{2}{|l|}{$\mathrm{CCR}<30 \mathrm{ml} / \mathrm{min}$} & \\
\hline & No. of Subject & $\%$ & No. of Subject & $\%$ & No. of Subject & $\%$ & \\
\hline 49 and below & 04 & 20 & 10 & 28 & 04 & 08 & 0.576 \\
\hline $50-59$ & 07 & 35 & 17 & 48 & 23 & 51 & 0.143 \\
\hline 60 and above & 09 & 45 & 08 & 22 & 18 & 40 & 0.632 \\
\hline
\end{tabular}

In our study population $64 \%$ subjects were male and $36 \%$ were female. No significant association between sex and outcome of ACS was observed.

Table II : shows distribution of different risk factors in all CCR groups and no significant association was observed among the groups.

\begin{tabular}{|c|c|c|c|c|c|c|c|}
\hline \multirow[t]{3}{*}{ Risk factors } & \multicolumn{2}{|c|}{ Group A } & \multicolumn{2}{|c|}{ Group B } & \multicolumn{2}{|l|}{ Group C } & \multirow[t]{3}{*}{ p- value } \\
\hline & \multicolumn{2}{|c|}{$\mathrm{CCR}>60 \mathrm{ml} / \mathrm{min}$} & \multicolumn{2}{|c|}{$\mathrm{CCR}=30-60 \mathrm{ml} / \mathrm{min}$} & \multicolumn{2}{|l|}{$\mathrm{CCR}<30 \mathrm{ml} / \mathrm{min}$} & \\
\hline & No. of Subject & $\%$ & No. of Subject & $\%$ & No. of Subject & $\%$ & \\
\hline Hypertension $(n=64)$ & 13 & 65 & 22 & 63 & 29 & 64 & 0.75 \\
\hline Smoking $(\mathrm{n}=61)$ & 12 & 60 & 22 & 62 & 27 & 60 & 0.91 \\
\hline Dyslipidemia $(n=51)$ & 10 & 50 & 18 & 51 & 23 & 51 & 0.56 \\
\hline Diabetes mellitus $(n=46)$ & 09 & 45 & 17 & 48 & 20 & 44 & 0.84 \\
\hline
\end{tabular}


Bangladesh Crit Care J March 2015; 3 (1): 3-6

Table III : shows distribution of clinical findings (anemia, basal crepitations in lungs and fever) among different CCR groups.

\begin{tabular}{|c|c|c|c|c|c|c|c|}
\hline \multirow[t]{3}{*}{ Clinical findings } & \multicolumn{2}{|c|}{ Group A } & \multicolumn{2}{|c|}{ Group B } & \multicolumn{2}{|l|}{ Group C } & \multirow[t]{3}{*}{ p- value } \\
\hline & \multicolumn{2}{|c|}{$\mathrm{CCR}>60 \mathrm{ml} / \mathrm{min}$} & \multicolumn{2}{|c|}{$\mathrm{CCR}=30-60 \mathrm{ml} / \mathrm{min}$} & \multicolumn{2}{|c|}{$\mathrm{CCR}<30 \mathrm{ml} / \mathrm{min}$} & \\
\hline & Jo. of Subject & $\%$ & No. of Subject & $\%$ & No. of Subject & $\%$ & \\
\hline Anemia $(n=23)$ & 02 & 10 & 04 & 11 & 17 & 37 & 0.001 \\
\hline Bilateral basal crepitation $(n=23)$ & 02 & 10 & 09 & 25 & 12 & 26 & 0.032 \\
\hline Fever $(n=10)$ & 00 & 00 & 02 & 06 & 08 & 17 & 0.039 \\
\hline
\end{tabular}

Table IV : shows outcome of the study subjects in different CCR groups

\begin{tabular}{|c|c|c|c|c|c|c|c|}
\hline \multirow{3}{*}{$\begin{array}{l}\text { Outcome of the } \\
\text { study subjects }\end{array}$} & \multicolumn{2}{|c|}{ Group A } & \multicolumn{2}{|c|}{ Group B } & \multicolumn{2}{|l|}{ Group C } & \multirow[t]{3}{*}{ p-value } \\
\hline & \multicolumn{2}{|c|}{$\mathrm{CCR}>60 \mathrm{ml} / \mathrm{min}$} & \multicolumn{2}{|c|}{$\mathrm{CCR}=30-60 \mathrm{ml} / \mathrm{min}$} & \multicolumn{2}{|l|}{$\mathrm{CCR}<30 \mathrm{ml} / \mathrm{min}$} & \\
\hline & No. of Subject & $\%$ & No. of Subject & $\%$ & No. of Subject & $\%$ & \\
\hline Stable $(n=26)$ & 15 & 75 & 8 & 22.8 & 3 & 6.6 & 0.022 \\
\hline $\operatorname{LVF}(\mathrm{n}=23)$ & 2 & 10 & 9 & 25.7 & 12 & 26.7 & 0.01 \\
\hline Hypotension(n=17) & 3 & 15 & 6 & 17.1 & 8 & 17.7 & 0.001 \\
\hline Bleeding $(\mathrm{n}=18)$ & 0 & 0 & 7 & 20 & 11 & 24.4 & 0.041 \\
\hline $\operatorname{Sepsis}(n=5)$ & 0 & 0 & 2 & 5.7 & 3 & 6.6 & 0.001 \\
\hline MODS* $(n=5)$ & 0 & 0 & 1 & 2.8 & 4 & 8.8 & 0.001 \\
\hline $\operatorname{Death}(\mathrm{n}=6)$ & 0 & 0 & 2 & 5.7 & 4 & 8.8 & 0.001 \\
\hline Total no. of subjects (100) & 20 & & 35 & & 45 & & \\
\hline
\end{tabular}

*multiple organ dysfunction syndrome

\section{Discussion}

It is well known that cardiovascular disease especially coronary heart disease has become number one cause of death and disability in 21 st century. With the improvement of people's life style, coronary artery disease has become a major cardiovascular morbidity among elderly people. Acute coronary syndrome has higher incidence of acute and severe symptoms, poor prognosis and high mortality compared with other types of heart disease and has become a serious threat to health of population..$^{3,22}$

Our study indicates that age has no relationship with severity of kidney function (Table I). And this distribution is similar to other studies ${ }^{1,3,15,23}$ found in medical literature.

Jurkovitz et al. ${ }^{24}$ suggested that high-risk patients of ACS could be identified by the presence of diabetes mellitus and hypertension and that a substantial decline in GFR mainly occurs in subjects with a baseline GFR $<30 \mathrm{ml} / \mathrm{min}$ per 1.73 $\mathrm{m}^{2}$. Our study subjects had hypertension (64\%), dyslipidaemia (51\%) and diabetes mellitus (46\%) as pre-existing risk factors of ACS (Table II). Sixty one percent subjects were smokers. No significant difference was observed among the three groups.

Jurkovitz et al. ${ }^{24}$ studied a prospective cohort of 13,329 middle-aged individuals without prior coronary heart disease. The authors demonstrated that patients with anemia (hemoglobin $[\mathrm{Hgb}]<13 \mathrm{~g} / \mathrm{dl}$ in men and $\mathrm{Hgb}<12 \mathrm{~g} / \mathrm{dl}$ in women) and elevated baseline $\mathrm{SCr}(\geq 1.2 \mathrm{mg} / \mathrm{dl}$ for women and $\geq 1.5 \mathrm{mg} / \mathrm{dl}$ for men) had a 2.7 -fold greater risk of AMI or death due to coronary heart disease compared with patients with normal serum creatinine. In our study twenty three percent subjects were anaemic. $23 \%$ subjects had bilateral basal crepitation. Fever was present in $10 \%$ subjects. Anaemia, bilateral basal crepitation and fever were more prevalent in group C. Significant difference was observed among the three groups (Table III). Wright et al. ${ }^{4}$, Gibson et al. ${ }^{7}$ and Wannamethee et al. ${ }^{9}$ also observed the similar presentations of ACS subjects.

A comparative study by Suwaidi et al. ${ }^{25}$ reported that renal dysfunction was associated with higher early risk of death or nonfatal AMI regardless of ST elevation status compared with patients with normal renal function. Another prospective multicenter study, GRACE ${ }^{26}$ study (Global Registry of Acute Coronary Events), analyzed 11,774 patients with STEMI, non-STEMI, and unstable angina and claimed that comparing with patients with normal or mildly impaired renal function, admission CrCL was independently associated with death; with an adjusted hazard ratio (AHR) of 3.71 for severe renal dysfunction and 2.09 for moderate renal dysfunction. Mielniczuk et al. ${ }^{27}$ studied 4178 patients with non-ST elevation ACS or STEMI from the A to Z trial and revealed impaired admission GFRs (CrCL $<60 \mathrm{ml} / \mathrm{min}$ ) were associated with a higher mortality after adjusting for baseline levels of highly sensitive C-reactive protein. Similar study by Cardarelli et al. ${ }^{28}$ claimed that severe renal dysfunction was associated with higher rates of death compared with normal renal function. Gibson et al. ${ }^{7}$ studied 13,307 patients and found impaired GFRs were associated with a poorer outcome in ACS subjects compared with maintained GFRs. Shlipak et al. ${ }^{6}$ evaluated 130,099 elderly patients with acute myocardial infarction (AMI). The authors observed that mild (admission serum creatinine between 1.5 and $2.4 \mathrm{mg} / \mathrm{dl}$ ) or moderate (admission serum creatinine between 2.5 and $3.9 \mathrm{mg} / \mathrm{dl}$ ) renal dysfunction were independent risk factors for death. At a 
1-month follow-up, the AHR for death was 1.68 for mild and 2.35 for moderate renal dysfunction compared with patients without CKD. Our study also observed significant difference in outcome among three different groups (Table IV). So we can assume that decreased creatinine clearance rate in subjects with ACS might increase in-hospital morbidity and mortality keeping in mind that creatinine clearance rate is not the only indicator of in -hospital outcome in subjects with ACS.

Our study was not without limitations. The sample size of the population was significantly small $(n=100)$ compared to different international studies. Our study period was only for 6 months involving only one centre.

We can conclude that not only severe type , but also mild to moderate renal insufficiency are independent predictors of in-hospital morbidity and mortality in patients hospitalized with ACS. Subjects with ACS should be closely monitored for decreasing creatinine clearance rate to avoid life threatening complications. Also subjects with renal impairment suffering from ACS should be closely observed because decreased CCR has poor clinical outcome. We recommend further study involving larger patient population across multiple centres to establish our conclusion.

\section{References}

1. SampsonJJ,Eliaser M Jr: The diagnosis of impending acute coronary artery occlusion.AmHeart J 1937;13:675-686.

2. Feil $\mathrm{H}$ : Preliminary pain in coronary thrombosis.Am J Sci 1937;193:42-48

3. Braunwald E. Unstable angina: classification. Circulation 1989; 80:410-4.

4. Wright RS, Reeder GS, Herzog CA, et al. Acute myocardial infarction and renal dysfunction: A high risk combination. Ann Intern Med 2002; 137:563 - 70.

5. Sørensen CR, Brendorp B, Rask-Madsen C, et al. The prognostic importance of creatinine clearance after acute myocardial infarction. Eur Heart J 2002; 23:948 - 52.

6. Shlipak MG, Heidenreich PA, Noguchi H, et al. Association of renal insufficiency with treatment and outcomes after acute myocardial infarction in elderly patients. Ann Intern Med 2002; 137:555 - 62.

7. Gibson CM, Pinto DS, Murphy SA, et al for the TIMI Study Group. Association of creatinine and creatinine clearance on presentation in Acute Myocardial Infarction with subsequent mortality. J Am CollCardiol 2003; 42:1535 -43.

8. Pitsavos C, Kurlaba G, Demosthenes B, et al. Association of Creatinine Clearance and In-Hospital Mortality in Patients With Acute Coronary Syndromes The GREECS Study. Circ J 2007; 71:9-14.

9. Wannamethee SG, Shaper AG, Perry IJ et al. Serum creatinine concentration and risk of cardiovascular disease: A possible marker for increased risk of stroke. Stroke 1997; 28:557-63.

10. Alcorn HG, Wolfson SK Jr, Sutton-Tyrrell K, et al. Risk factors for abdominal aortic aneurysms in older adults enrolled in the cardiovascular health study. ArteriosclerThrombVascBiol 1996; 16:963-70.

11. Gottlieb SS, Mc Carter RJ, Vogel RA et al. Effect of beta-blockade on mortality among high risk and low risk patients after myocardial infarction. N Engl J Med 1998; 339:489-97.

12. Pahor M, Shorr RI, Somes GW, et al. Diuretic-based treatment and cardiovascular events in patients with mild renal dysfunction enrolled in the systolic hypertension in the elderly program. Arch Intern Med 1998; 158:1340-5.
13. Culleton BF, Larson MG, Wilson PW,et al. Cardiovascular disease and mortality in a community-based cohort with mild renal insufficiency. Kidney Int 1999; 56:2214-9.

14. K/DOQI clinical practice guidelines for chronic kidney disease: evaluation, classification, and stratification. Am J Kidney Dis 2002; 39:S1.

15. Sarnak MJ, Levey AS, Schoolwerth AC, et al. Kidney disease as a risk factor for development of cardiovascular disease: a statement from the American Heart Association Councils on Kidney in Cardiovascular Disease, High Blood Pressure Research, Clinical Cardiology, and Epidemiology and Prevention. Hypertension 2003; 42:1050-65.

16. Tonelli M, Wiebe N, Culleton B, et al. Chronic kidney disease and mortality risk: a systematic review. J Am SocNephrol 2006; 17:2034-47.

17. Muntner P, He J, Hamm L, et al. Renal insufficiency and subsequent death resulting from cardiovascular disease in the United States. J Am SocNephrol 2002; 13:745-53.

18. Manjunath G, Tighiouart H, Ibrahim H, et al. Level of kidney function as a risk factor for atherosclerotic cardiovascular outcomes in the community. J Am CollCardiol 2003; 41:47-55.

19. Anavekar NS, McMurray JJ, Velazquez EJ, et al. Relation between renal dysfunction and cardiovascular outcomes after myocardial infarction. N Engl J Med 2004; 351:1285-95.

20. Go AS, Chertow GM, Fan D, et al. Chronic kidney disease and the risks of death, cardiovascular events, and hospitalization. N Engl J Med 2004; 351:1296305.

21. Weiner DE, Tighiouart H, Amin MG, et al. Chronic kidney disease as a risk factor for cardiovascular disease and all-cause mortality: a pooled analysis of community-based studies. J Am SocNephrol $2004 ; 15: 1307-15$.

22. Landray MJ, Thambyrajah J, McGlynn FJ, et al. Epidemiological evaluation of known and suspected cardiovascular risk factors in chronic renal impairment. Am J Kidney Dis 2001; 38:537-46.

23. Ninomiya T, Kiyohara Y, Kubo M, et al. Chronic kidney disease and cardiovascular disease in a general Japanese population: The Hisayama Study. Kidney Int 2005; 68: $228-36$

24. Jurkovitz CT, Abramson JL, Vaccarino LV, et al: Association of high serum creatinine and anemia increases the risk of coronary events: Results from the prospective community-based atherosclerosis risk in communities (ARIC) study. J Am Soc Nephrol 2003; 14: 2919-25.

25. Suwaidi J, Reddan DN, Williams K, et al. Prognostic implications of abnormalities in renal function in patients with acute coronary syndromes. Circulation 2002; 106: 974-80.

26. Santopinto JJ, Fox KA, Goldberg RJ, et al; Creatinine clearance and adverse hospital outcomes in patients with acute coronary syndromes: Findings from the global registry of acute coronary events (GRACE). Heart 2004; 89: 1003-8.

27. Mielniczuk LM, Pfeffer MA, Lewis EF, et al: Estimated glomerular filtration rate, inflammation, and cardiovascular events after an acute coronary syndrome. Am Heart J 2008; 155: 725-31.

28. Cardarelli F, Bellasi A, Shaw LJ, et al: Combined impact of age and estimated glomerular filtration rate on in-hospital mortality after percutaneous coronary intervention for acute myocardial infarction (from the American College of Cardiology National Cardiovascular Data Registry). Am J Cardiol 2009; 103: 766-71. 